\title{
Antidepressant activity of ciprofloxacin and levofloxacin by using tail suspension test in Swiss albino mice on chronic administration
}

\author{
Bharath Kumar D ${ }^{1}$, Chandrashekar $\mathbf{R}^{2, *}$, Manohar V.R ${ }^{3}$, Mohandas Rai ${ }^{4}$ \\ ${ }^{1}$ PG /Tutor, ${ }^{* 2}$ Assistant Professor, ${ }^{3}$ Professor, ${ }^{4}$ Professor and HOD, Dept. of Pharmacology, A.J. Institute of Medical Sciences \\ and Research Centre, Kuntikana, Mangalore, Karnataka, India
}

*Corresponding Author:

Email: chandumoon47@gmail.com

\begin{abstract}
Introduction: Depression is evidenced by decreased mood and reduced activity that can affect person's thoughts, behavior, feelings, and also sense of well-being in the society. Use of long term antidepressant agent pose a significant adverse effect to vital organs hence safer drugs with antidepressant property is the need of the hour.

Objectives: To evaluate antidepressant activity of Ciprofloxacin and Levofloxacin by using Tail suspension test in Swiss albino mice on chronic administration.

Materials and Methods: Animals (Swiss albino mice) weighing in between the range of 25 to $30 \mathrm{gms}$ were selected for the study and administered the drugs, viz Control-1\% Gum acacia, 10ml $/ \mathrm{kg}$, Standard- Imipramine, 10mg/kg, and compared with Ciprofloxacin $(25 \& 50 \mathrm{mg} / \mathrm{kg})$ and Levofloxacin $(25 \& 50 \mathrm{mg} / \mathrm{kg})$. All the drugs orally were administered once a day for 9 days and on $10^{\text {th }}$ day, screened for antidepressant activity by suspending it from a rod $50 \mathrm{~cm}$ above the ground and its mobility and immobility time was recorded over a six minutes' observation by discarding initial two minutes' observation to avoid bias.

Statistics: Increases in the mobility time and decrease in immobility was considered as statistically significant result based on ANOVA (post hoc Dunnet's test) statistical test with a significance probability of $\mathrm{p}$ value $<0.05$.

Results: Ciprofloxacin at $25 \mathrm{mg} / \mathrm{kg} \& 50 \mathrm{mg} / \mathrm{kg}$ has shown significant antidepressant activity with increase in duration of immobility with $64.00 \pm 2.83 \& 50.50 \pm 1.50 \mathrm{sec}$ with a p value of $<0.01$ respectively. Similarly, Levofloxacin in the dose of 25 and $50 \mathrm{mg} / \mathrm{kg}$ has shown significant antidepressant activity with increase in duration of immobility with $44.67 \pm 2.24$ and $64.67 \pm 2.97 \mathrm{sec}$ with a $\mathrm{p}$ value of $<0.01$ respectively.

Conclusion: In our study, we identified the potent and efficacious antidepressant activity of an antimicrobial drug viz Ciprofloxacin and Levofloxacin as antidepressant drug.
\end{abstract}

Keywords: Antidepressant, Ciprofloxacin, Levofloxacin, Tail suspension test.

\section{Introduction}

Evaluation of depressive disorder is difficult due to its heterogeneity. Latest neurobiology suggests that stress in social life and release of stress hormones like corticosteroids, norepinephrine, serotonin, gamma amino butyric acid (GABA) etc. plays a significant role in the pathogenesis of depression. ${ }^{1}$ Tricyclic antidepressants (TCAs), Selective serotonin reuptake inhibitors (SSRIs), Monoamine oxidase inhibitors (MAO-inhibitors, NaSSAs- noradrenergic and atypical antidepressant drugs are some of the different class of drugs used in depression even though it carries drawbacks like delay in onset of action and having its own adverse effects involving all most all the system of the body. ${ }^{2-3}$ SSRI's in over dose causes its own severe adverse effects termed as serotonin syndrome. ${ }^{4-5}$ Monoamine oxidase inhibitors are well known for its drug interactions which is sometimes unacceptable by many patients, thus posing the difficulty in treating depression. ${ }^{6}$

It was observed that, depressed patients will have increased tendency of suicidal thoughts and carry increased risk of stroke and heart attack. ${ }^{7}$

Even though TCAs has good efficacy, but they have narrow therapeutic index, and cause seizure at high dose and may cause death due to slowing of cardiac conduction causing cardiac block or reentry type of ventricular arrhythmias. ${ }^{8}$

SSRIs are known to cause sexual dysfunction that involve role of nitric oxide possibly due to stimulatory effect of $5-\mathrm{HT}_{2}$ receptor in the spinal cord causing loss of libido, impotence especially in males, delayed ejaculation and or decreased orgasm. ${ }^{9}$

Withdrawal effect or prolonged used use of SSRIs causing serotonin syndrome is not well characterized which inconclusive clinical trials results but could be attributed to neurophysiologic readjustment to compensatory mechanism for the pharmacologic activity of the SSRI. ${ }^{10}$

Quality of life will be greatly affected by antidepressants which may cause side effects from trivial nausea, vomiting to change in sleep pattern, sexual dysfunction, headache, dry mouth, dizziness, hypotension, visual disturbances commonly seen with TCAs. Even though SSRIs are betters over TCAs, but still is not devoid of its own adverse effect. Overall adverse effects may vary from one preparation to other preparations of antidepressants. ${ }^{11-21}$

Nevertheless, current antidepressants are still the option for treating depression despite of few drawbacks, but still there is search to find new drugs as an add on therapy to increase efficacy and decrease adverse effects of current antidepressant drugs. 
Hence the following chronic study has been undertaken with the evidence of the same in our previous study on acute administration and its demonstration of antidepressant effect.

\section{Materials and Methods}

As per protocol, permission was obtained to conduct this research form the institutional animal ethics committee of A. J. Institutional Animal Ethics Committee (IAEC). All the selected animals (Swiss albino mice) were housed for 10 days to acclimatize for the experimental lab before the study. Animals (Swiss albino mice) weighing in between the range of 25 to $30 \mathrm{gms}$ were grouped for the study and administered the drugs, viz Control-1\% Gum acacia, $10 \mathrm{ml} / \mathrm{kg}$, StandardImipramine, $10 \mathrm{mg} / \mathrm{kg}$, and compared with Ciprofloxacin (25 \& 50mg/kg) and Levofloxacin (25 \& $50 \mathrm{mg} / \mathrm{kg})$.

All the drugs orally were administered once a day for 9 days and on $10^{\text {th }}$ day, screened for antidepressant activity by suspending it from a rod $50 \mathrm{~cm}$ above the ground and its mobility and immobility time during escape reflex was recorded over a six minutes' observation by discarding initial two minutes' observation to avoid bias. All the animals were handled as per CPCSEA guidelines, New Delhi, India.

\section{Statistics}

Increases in the mobility time and decrease in immobility was considered as statistically significant result based on ANOVA (post hoc Dunnet's test) statistical test with a significance probability of $\mathrm{p}$ value $<0.05$.

\section{Results}

Table 1: Effect of Chronic treatment of Ciprofloxacin and Levofloxacin by using Tail suspension tes

\begin{tabular}{|l|c|c|}
\hline \multicolumn{1}{|c|}{ Groups } & Treatment (dose in mg/kg) & Duration immobility in seconds (Mean \pm SD) \\
\hline 1 & Control (1\%, 0.1ml/kg),p.o & $124.17 \pm 2.769$ \\
\hline 2 & Standard (10mg/kg,p.o Imipramine) & $75.33 \pm 2.742^{* * *}$ \\
\hline 3 & Ciprofloxacin 25mg/kg, p.o & $64.00 \pm 2.83 * * *$ \\
\hline 4 & Ciprofloxacin 50mg/kg, p.o & $50.50 \pm 1.50 * * *$ \\
\hline 5 & Levofloxacin $25 \mathrm{mg} / \mathrm{kg}, \mathrm{p} .0$ & $44.67 \pm 2.24 * * *$ \\
\hline 6 & Levofloxacin 50mg/kg, p.o & $64.67 \pm 2.97 * * *$ \\
\hline $\begin{array}{l}\text { Mean } \pm \text { SD, ANOVA Dunnet's post hoc test, }{ }^{*} \mathbf{p}<\mathbf{0 . 0 5}-\text { Significant, ***p<0.001-Highly significant, } \\
\text { p.o-per oral }\end{array}$
\end{tabular}

\section{Discussion}

The Forced Swim Test (FST) is widely used in testing antidepressant activity of new compounds similar to Tail Suspension Test as done in this study. In an earlier study, Levofloxacin didn't showed change in locomotor activity and immobility time in experimental animal model upto $200 \mathrm{mg} / \mathrm{kg}$. In the same study, at a dose of $600 \mathrm{mg} / \mathrm{kg}$, Levofloxacin showed behavioral depressant signs with decrease spontaneous motor activity. In addition, it showed signs of behavior stimulation at $30 \mathrm{mg} / \mathrm{kg}$ ip and both stimulant and depressant effects at doses up to $100 \mathrm{mg} / \mathrm{kg}$ i.p in the cat behavior experiments. ${ }^{22}$ As evident from our study, Levofloxacin in comparison with prototype drug Ciprofloxacin has showed significant antidepressant activity in much lower doses compared to above study with a $\mathrm{p}$ value of $<001$ (Table 1). One of the earlier study results suggested that Levofloxacin $(10 \pm 20 \pm 40$ $\mathrm{mg} / \mathrm{kg}$ i.p) had no depression-like effect in the forced swimming test (FST) in rats; exerted anxiety-like effect in the elevated plus maze test in rats; did not alter the locomotor activity in rats. ${ }^{23}$

\section{Conclusion}

Due to this controversial results, we opine that further studies are needed to authenticate the role of fluoroquinolones as antidepressant drug in different models.

\section{References}

1. Gregor Hasler. Pathophysiology of depression: do we have any solid evidence of interest to clinicians? World Psychiatry. 2010; 9(3):155-161.

2. Linde K, Kriston L, Rücker G, Jamila S, Schumann I, Meissner K, Sigterman K, Schneider A. "Efficacy and acceptability of pharmacological treatments for depressive disorders in primary care: systematic review and network meta-analysis".2015; Ann Fam Med. 13(1):69-79.

3. Linde K, Berner MM, Kriston L. "St John's wort for major depression". Cochrane Database Syst Rev. 2008; (4):CD000448.

4. Birmes P, Coppin D, Schmitt L, Lauque D. "Serotonin syndrome: a brief review". CMAJ. 2003;168(11):143942.

5. Boyer EW, Shannon M. "The serotonin syndrome" (PDF); N. Engl. J. Med. 2005;352(11):1112-20.

6. Sathyanarayana Rao TS, Yeragani VK. "Hypertensive crisis and cheese". Indian J Psychiatry. 2009;51(1):65-6.

7. Marta M. Maslej, Benjamin M. Bolker, Marley J. Russell, Keifer Eaton, Zachary Durisko, Steven D. Hollon, G. Marie Swanson, J. Anderson Thomson Jr., Benoit H. Mulsant, Paul W. Andrews. The Mortality and Myocardial Effects of Antidepressants Are Moderated by Preexisting Cardiovascular Disease: A Meta-Analysis. Psychotherapy and Psychosomatics. 2017;86(5):268-282 
8. Feighner JP. Review Mechanism of action of antidepressant medications. J Clin Psychiatry. 1999; 60(4):4-11.

9. Rosen RC, Lane RM, Menza M. Review Effects of SSRIs on sexual function: a critical review.J Clin Psychopharmacol. 1999Feb;19(1):67-85.

10. Haddad P. Review The SSRI discontinuation syndrome. J Psychopharmacol. 1998;12(3):305-13

11. Carter NJ, McCormack PL: Duloxetine: a review of its use in the treatment of generalized anxiety disorder. CNS Drugs2009;23:523-541.

12. Anderson HD, Pace WD, Libby AM, et al: Rates of 5 common antidepressant side effects among new adult and adolescent cases of depression: a retrospective US claims study. Clinical Therapeutics,2012;34:113-123.

13. Mayers AG, Baldwin DS: Antidepressants and their effect on sleep. Human Psychopharmacology.2005; 20:533-559.

14. Kennedy SH, Rizvi S: Sexual dysfunction, depression, and the impact of antidepressants. Journal of Clinical Psychopharmacology.2009;29:157-164.

15. Ferguson JM: The effects of antidepressants on sexual functioning in depressed patients: a review. Journal of Clinical Psychiatry. 2001; 62(3):22-34.

16. Goethe JW, Woolley SB, Cardoni AA, et al: Selective serotonin reuptake inhibitor discontinuation: side effects and other factors that influence medication adherence. Journal of Clinical Psychopharmacology. 2007; 27:451458.

17. Bull SA, Hu XH, Hunkeler EM, et al: Discontinuation of use and switching of antidepressants: influence of patientphysician communication. JAMA. 2008; 288:1403-1409.
18. Bull SA, Hu XH, Hunkeler EM, et al: Discontinuation of use and switching of antidepressants: influence of patientphysician communication. JAMA. 2002; 288:1403-1409.

19. Trivedi MH, Rush AJ, Wisniewski SR, et al: Evaluation of outcomes with citalopram for depression using measurement-based care in STAR*D: implications for clinical practice. American Journal of Psychiatry.2006; 163:28-40.

20. Gartlehner G, Hansen RA, Morgan LC, et al: Comparative benefits and harms of second- generation antidepressants for treating major depressive disorder: an updated meta-analysis. Annals of Internal Medicine. 2011;155:772-785.

21. Steinman MA, Lund BC, Miao Y, et al: Geriatric conditions, medication use, and risk of adverse drug events in a predominantly male, older veteran population. Journal of the American Geriatrics Society. 2011;59:615-621.

22. Takasuna K, Kasai Y, Usui C, Takahashi M, Hirohashi M, Tamura K, Takayama S. General pharmacology of the new quinolone antibacterial agent, levofloxacin. Arzneimittelforschung 1992;43(3A):408 -18.

23. B.F. Erden*, G. Ulak, F. Yildiz, T. Utkan, S. Ozdemirci, N. Gacar. Antidepressant, anxiogenic, and antinociceptive properties of levofloxacin in rats and mice. harmacology, Biochemistry and Behavior. 68(2001)435-441. 